\title{
Optical parameters of amorphous arsenic triselenide multilayers prepared by spin coating
}

\author{
Salah. M .M.Salman ${ }^{1,2}$ \\ ${ }^{1}$ Educational Services, Qassim University, Ministry of High Education, Kingdom of Saudi Arabia \\ ${ }^{2}$ Physics Department, Faculty of Science, Helwan University, Ain-Helwan

\section{Abstract} \\ Multilayer thin films of amorphous arsenic triselenide $\left(\mathrm{As}_{2} \mathrm{Se}_{3}\right)$ were obtained by spin coating solution of an amine salt in \\ amide on glass substrate. The deposited multilayers in the range of 500 to $1000 \mathrm{~nm}$ were optically characterized by \\ measuring the transmission spectra at room temperature. All used samples were baked and annealed for different \\ periods of times and temperatures. The effect of layers number, baking times and temperatures on optical parameters \\ were investigated. The thickness of the prepared samples up to four layers was ranging between $0.1 \mu \mathrm{m}$ to $0.2 \mu \mathrm{m}$.

\section{Key words} \\ amorphous arsenic triselenide, optical parameters

\section{Introduction} \\ Amorphous arsenic triselenide is the most widely used model system for the study of amorphous semiconductors [1, 2]. \\ This material is known for its important applications in the fields of high-resolution lithography, switching devices and \\ optical memories, thin film optical waveguides and acousto-optic devices. It has also the most important chalcogenide \\ semiconductors that serve as a direct reference in the discussion of the optical properties of these materials [3]. From \\ both the theoretical and experimental point of view, it is important to know the optical constants of the considered material. \\ All these constants are strongly dependent on the sample preparation technique. Vacuum deposition and sputtering \\ techniques have been widely used in preparing chalcogenide films. In a previous work, the spin coating from organic \\ solutions is a convenient and effective method to prepare flat thin films of arsenic trisulfide thin films. Amorphous \\ chalcogenides deposited in this way have been successfully used for high-resolution lithography [4, 5]. The optical \\ constants of a thin film as well as the optical band gap explain the significant interest of these materials for a specific \\ application. In the present work, we report the formation of multilayer amorphous arsenic chalcogenide films using the \\ solvent cast technique (spin- coating). The optical constants of the prepared films have been determined by analyzing the \\ transmittance spectra. Also the effect of baking, annealing time and temperature on the solvent cast materials and their \\ optical parameters are studied.
}

\section{Experimental technique}

The solvent-coast technique has been used to prepare thin film amorphous chalcogenide samples for some decades [6]. This technique involves two steps for the preparation of the solution. In this study, the chalcogenide $\mathrm{As}_{2} \mathrm{Se}_{3}$ is obtained from the melt quench of As and Se with impurity $99.999 \%$. The product was crushed under clean environment to obtain $\mathrm{As}_{2} \mathrm{Se}_{3}$ powder. The powder was dissolved in amines as a first step to obtain the amine salt of chalcogenide. After dissolving the chalcogenide powders in the amine solvent, the solution is dried in a furnace warmed between 30 and $60{ }^{\circ} \mathrm{C}$ for 24 hours. Then an amide solvent was used as a second step to obtain the chalcogenide solution. The dried salt powders are then dissolved in the amide. The amide solution is used for spin coating. The spin-coating process was carried out at 2000- $3000 \mathrm{rev} / \mathrm{min}$ for 30 seconds on a flat glass substrate. The samples were baked at $90^{\circ} \mathrm{C}$ for $20 \mathrm{~min}$ and then further baked at $120{ }^{\circ} \mathrm{C}$ for another $20 \mathrm{~min}$ to remove the volatile. The spin-coating films obtained from this technique were found to possess a smoother surface than those were obtained from amine solution. A typical film thickness of $0.1 \mu \mathrm{m}$ was obtained. Films as thick as $0.2 \mu \mathrm{m}$ were obtained by varying the concentration of the amide solution. In this fashion, flat multilayers of $\mathrm{As}_{2} \mathrm{Se}_{3}$ with thickness up to $0.2 \mu \mathrm{m}$ have been obtained. The transmission spectrum was measured at room temperature using a double beam Unicom VIS/NIR spectrometer in the wave length range $500-1000 \mathrm{~nm}$. Optical characterization and thickness of the spin- coated thin $\mathrm{As}_{2} \mathrm{Se}_{3}$ film were performed with the help of transmission curves obtained. Almost all the films under investigation have proven to be uniform in thickness showing clear interference fringes due to multilayer reflections at the interface. Otherwise, the fringes should have been destroyed showing smooth transmission curves [7]. The thickness and optical constants of all the prepared films were calculated in the transparent region. A typical transmission spectrum, representing the behavior of all the measured samples is shown in Figure (1). 


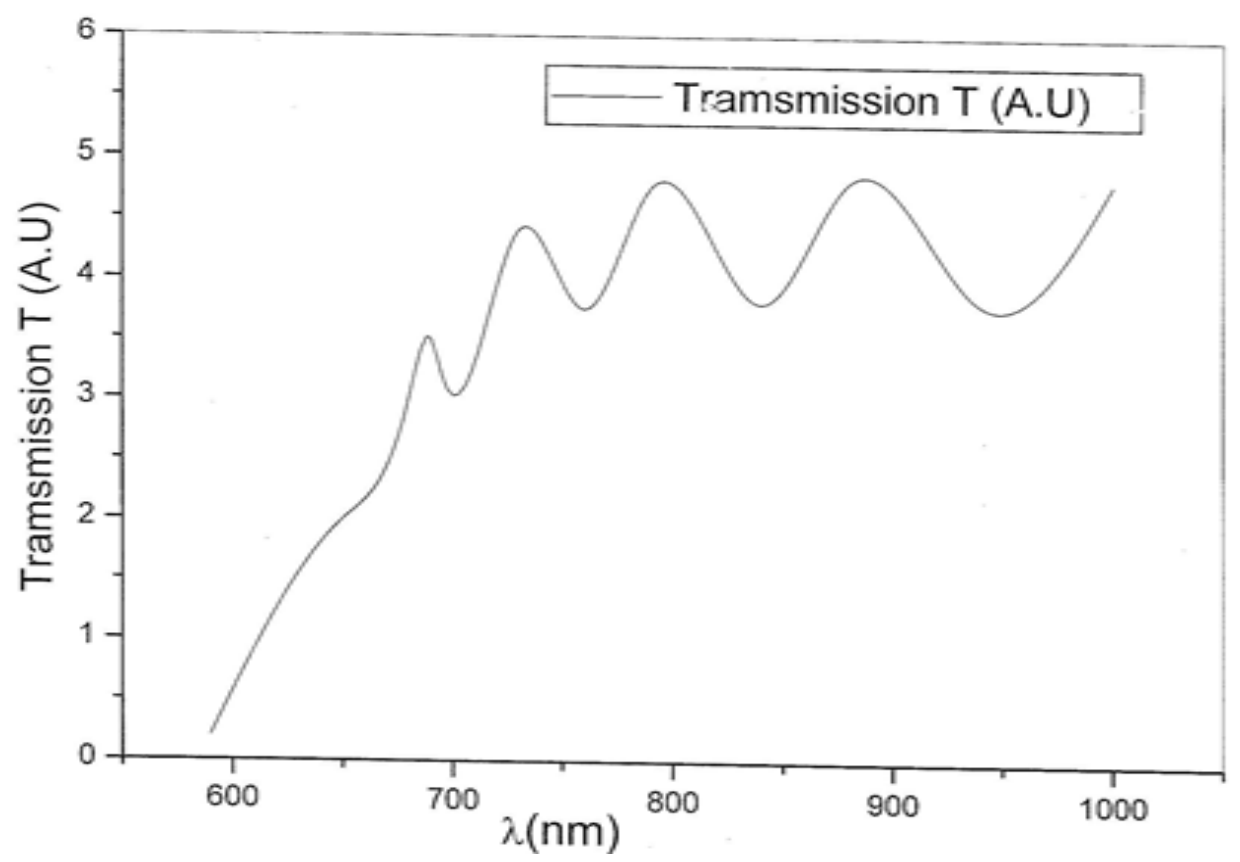

Fig. 1:- transmission curves (transmission versus wave length)

\section{Results and discussions}

The transmission spectrum of the multilayers spin- coated samples is recorded. The thin film is of a thickness, $d$, and a complex refractive index $n_{c}=n_{1}-i k$, where $n_{1}$ is the refractive index and $k$ is the extinction coefficient. If $n_{2}$ is the refractive index of the transparent substrate, then the transmittance can be given by the expression [4]:

$$
\mathrm{T}=\left[8 \mathrm{n}_{0}\left(\mathrm{n}_{1}^{2}+\mathrm{k}_{1}^{2}\right) \mathrm{n}_{2}\right] /[\mathrm{A} \cosh \gamma+\mathrm{B} \sinh \gamma+C \cos \delta+D \sin \delta]
$$

Where

$$
\begin{gathered}
\gamma=\left(4 \pi \mathrm{k}_{1} \mathrm{~d}\right) / \lambda_{0} \\
\delta=\left(4 \pi \mathrm{n}_{1} \mathrm{~d}\right) / \lambda_{0} \\
\mathrm{~A}=\left(\mathrm{n}_{1}^{2}+\mathrm{k}_{1}^{2}+\mathrm{n}_{0}^{2}\right)\left(\mathrm{n}_{1}^{2}+\mathrm{k}_{1}^{2}+\mathrm{n}_{2}^{2}\right)+2 \mathrm{n}_{1}^{2}\left(\mathrm{n}_{0}^{2}+\mathrm{n}_{2}^{2}\right) \\
\mathrm{B}=\left(\mathrm{n}_{0}+\mathrm{n}_{2}\right)\left(2 \mathrm{n}_{1}{ }^{2}+2 \mathrm{k}_{1}{ }^{2}+\mathrm{n}_{0}{ }^{2}+\mathrm{n}_{2}{ }^{2}\right) \\
\mathrm{C}=\left(\mathrm{n}_{1}^{2}+\mathrm{k}_{1}{ }^{2}-\mathrm{n}_{0}{ }^{2}\right)\left(\mathrm{n}_{1}{ }^{2}+\mathrm{k}_{1}{ }^{2}-\mathrm{n}_{2}{ }^{2}\right)-4 \mathrm{k}_{1}{ }^{2} \mathrm{n}_{0} \mathrm{n}_{2} \\
\mathrm{D}=\mathrm{k}_{1}\left(\mathrm{n}_{0}{ }^{2}+\mathrm{n}_{2}{ }^{2}\right)\left(\mathrm{n}_{1}{ }^{2}+\mathrm{k}_{1}{ }^{2}-\mathrm{n}_{0} \mathrm{n}_{2}\right)
\end{gathered}
$$

With $\lambda_{0}$ being the wavelength and $n_{0}$ is the refractive index of air. If the thin film is almost transparent, the transmittance T can be approximated to:

$T=\left[8 n_{0} n_{1}^{2} n_{2}\right] /\left[\left(n_{0}^{2}+n_{1}^{2}\right)\left(n_{1}^{2}+n_{2}^{2}\right)+2 n_{1}^{2}\left(n_{0}^{2}+n_{2}^{2}\right)-\left(n_{1}^{2}-n_{0}^{2}\right)\left(n_{1}^{2}-n_{2}^{2}\right) \cos \delta\right]$

The wavelengths of the fringe maxima and the corresponding minima are given by:

$$
\begin{array}{ll}
\lambda_{\max }=\left(2 \mathrm{n}_{1} \mathrm{~d}\right) / \mathrm{m} & \text { at the fringe maximum } \\
\lambda_{\min }=\left(4 \mathrm{n}_{1} \mathrm{~d}\right) /(2 \mathrm{~m}+1) & \text { at the fringe minimum }
\end{array}
$$

\subsection{Determination of the studied films thickness}

The thickness of the prepared films has been determined from the transmission curves represented in Figure (1) using the well-known relation [7]:

$$
d=\left(\lambda_{1} \lambda_{2}\right) / 2\left(n_{1} \lambda_{1}-n_{1} \lambda_{2}\right)
$$

Where $n_{1}$ and $n_{2}$ are the refractive indices at the two adjacent (maxima or minima) $\lambda_{1}$ and $\lambda_{2}$. The results obtained for $d$ (in the range $0.1-0.2 \mu \mathrm{m}$ ) were confirmed by the graphical method used to determine the thickness using the basic 
equation for interference fringes [9]: $2 \mathrm{n} \mathrm{d}=\mathrm{m} \lambda$, where $\mathrm{m}$ is an integer for maxima and half integer for minima. This technique is beyond the scope of the present work; nevertheless, Swanepoel gives the details in reference [9].

\subsection{Refractive index and the absorption coefficient of the $\mathrm{As}_{2} \mathrm{Se}_{3}$ spin- coated thin films}

Following Swanepoel [9] and the above treatment of the transmittance, the refractive indices of the films under investigation are calculated and presented in Figure (2) as a function of wavelength. The figure shows the refractive index dispersion for four samples having one- layer, two- layer, three- layer and four- layers, prepared from the same solvent. The scattering in the refractive index data could be due to fluctuations in the baking temperature and dilution in the solvent. Although these factors have been kept minimal, however, the refractive index seems to be independent of the thickness and the number of layers. The experimental results have been fitted by the Sellmeier formula with one oscillator, which is given by [10-14]:

$$
n_{1}^{2}-1=\left(E_{d} E_{0}\right) /\left(E_{0}^{2}-E^{2}\right)
$$

Where $\mathrm{n}$ is the refractive index, $E_{d}$ is the dispersion energy (representing an energy parameter of the complex electronic dielectric constant which is related to the inter band transition strength). It does not depend on either the band or the volume density of the valence electrons.

The characteristic oscillator energy, $E_{0}$, in the Sellmeier formula is defined by the mean transition energy from the valence band to the conduction state. The values of $E_{d}$ and $E_{0}$ can be determined directly from the slop $\left(E_{d} E_{0}\right)^{-1}$ and the interaction of the linear dependence of $\left(n_{1}^{2}-1\right)^{-1}$ versus $E$ as shown in Figure (3).

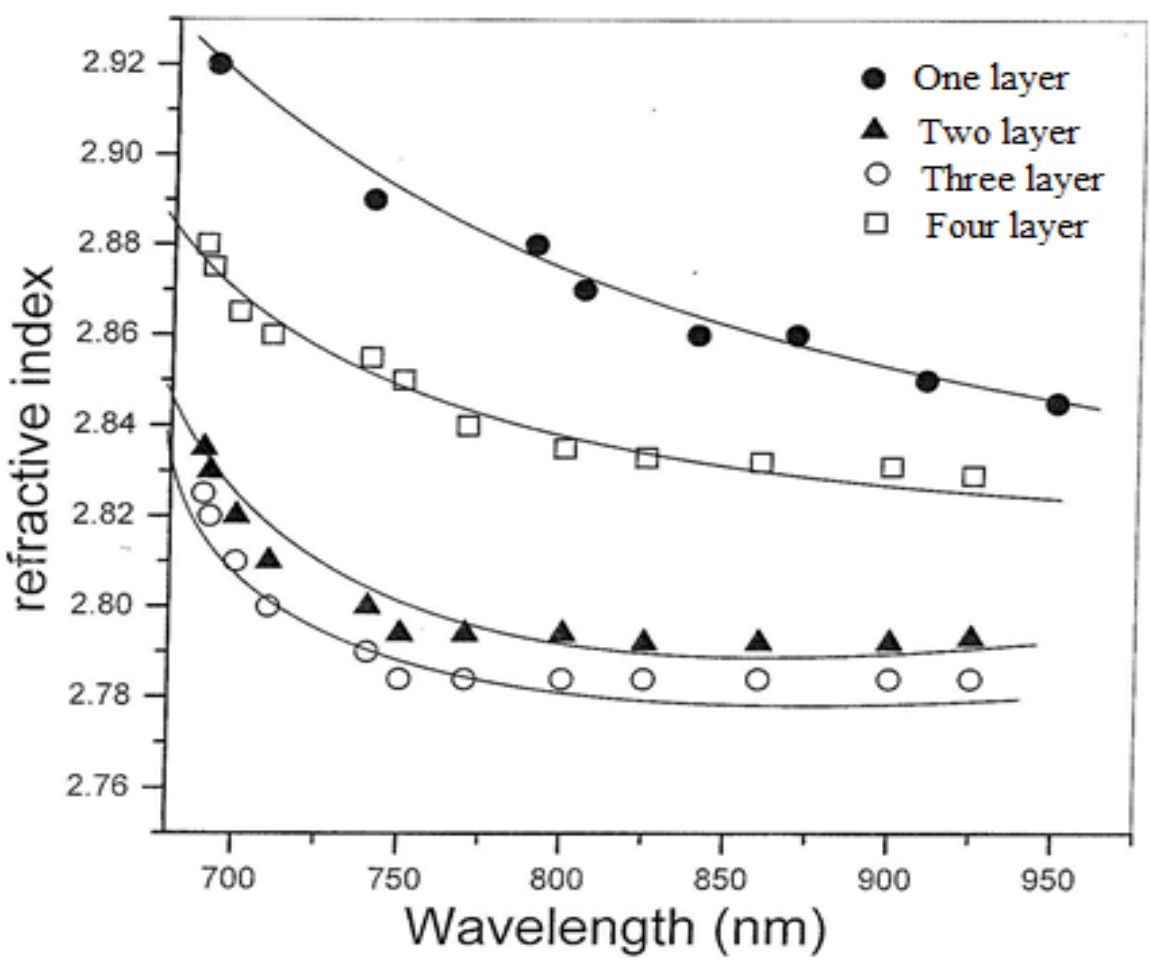

Fig. 2:- refractive index versus wave length 


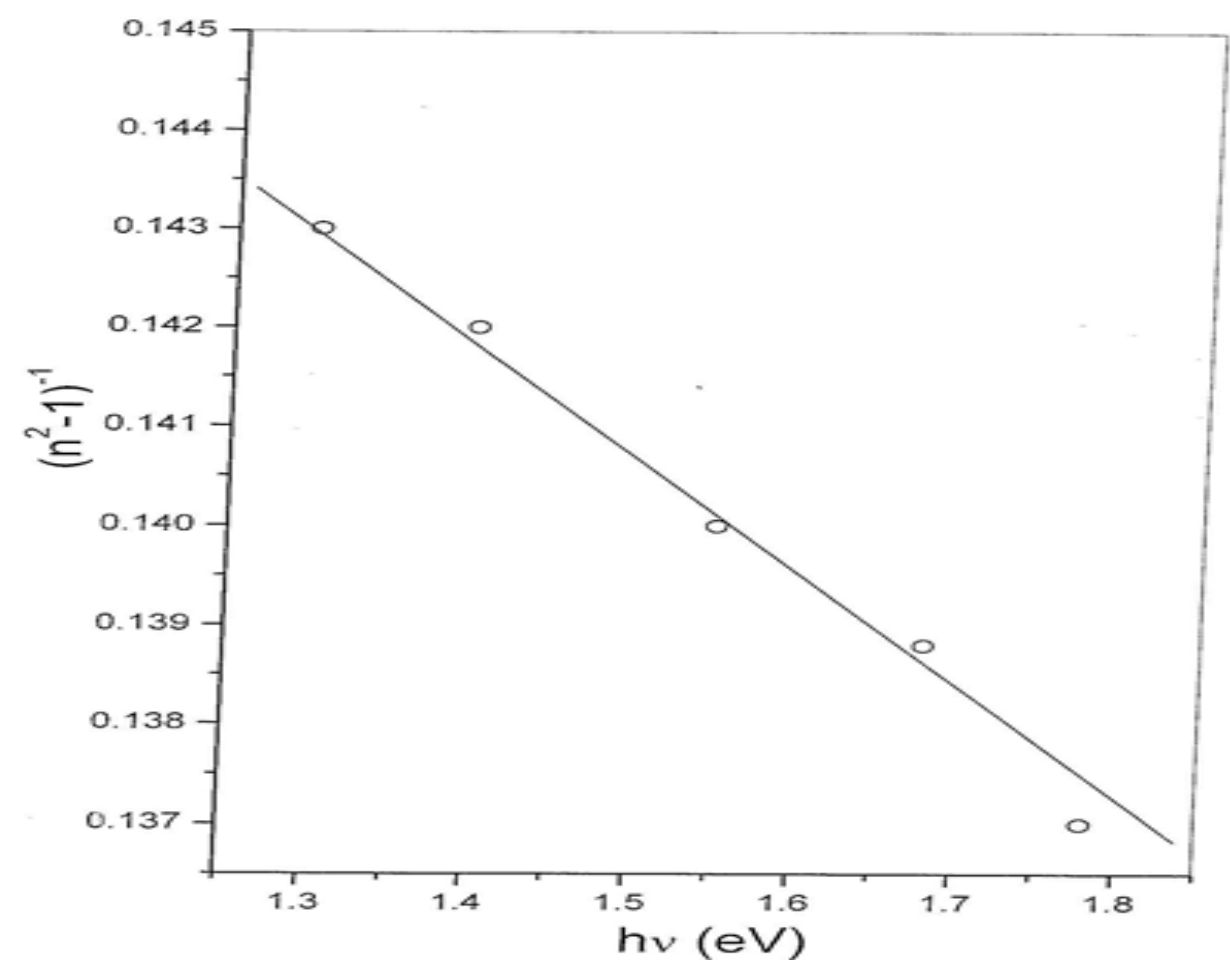

Fig. 3: $\left(n_{1}{ }^{2}-1\right)^{-1}$ versus $E$

The characteristic oscillator energy, $\mathrm{E}_{0}$, in the Sellmeier formula is found to be $4.62 \mathrm{eV}$ which is in a very good agreement with that reported for $\mathrm{As}_{2} \mathrm{Se}_{3}$ [15]. This value is smaller than that reported for sputtered or evaporated films reflecting the different deposition technique.

The absorption coefficient of the $\mathrm{As}_{2} \mathrm{Se}_{3}$ multilayer films near the absorption edge was obtained from the transmittance spectra. The absorption coefficient of the multilayer films up to four layers is shown in Figure (4). It is clear that, the absorption coefficient tends to decrease with the film thickness. The square root of $\alpha$ hv was found to increase linearly with photon energy in the region where $\alpha$ was higher than $10^{-3} \mathrm{~cm}^{-1}$. A plot of $(\alpha \mathrm{hv})^{1 / 2}$ as a function of photon energy (hv) is shown in Figure (5). This behavior was found to follow Tauc's relation [16]:

$$
\alpha h v=B\left(h v-E_{g}\right)^{2}
$$

Where $B$ is a constant. This dependence indicates the existence of indirect transition in this region.

The optical energy gap in Figure (5) is given by the extrapolation of the $(\alpha h v)^{1 / 2}$ versus photon energy graph to $(\alpha h v)^{1 / 2}=$ 0 . The constant $B^{1 / 2}$ is determined from the slope of linear part of Tauc's relation. It was found $B^{1 / 2}\left(\mathrm{~cm}^{-1} \mathrm{eV}^{-1}\right) \mathrm{ranges}$ between 268 and $360\left(\mathrm{~cm}^{-1} \mathrm{eV}^{-1}\right)$ for samples with different number of layers. $\mathrm{B}^{1 / 2}$ was reported to be between 600 and 640 for $\mathrm{As}_{2} \mathrm{Se}_{3}$ thin films doped with different concentrations of silver, prepared by thermal evaporation technique [17]. The difference between these reported values and those obtained in this work is due to the difference in the preparation technique and doping the films with silver. These values are also a little less than those reported for $\mathrm{As}_{2} \mathrm{Se}_{3}$ films prepared by thermal evaporation or sputtering technique. These differences are most likely due to the polarizable organic solvent residues in the spin- cast materials.

\subsection{Annealing effects on the films}

Annealing of the films is expected to affect the optical parameters since the organic residue content is a strong function of the baking temperature [4]. All the samples were baked for $15 \mathrm{~min}$ in a small oven after spin- coating. The refractive index of the films baked at $180^{\circ} \mathrm{C}$ is found to be close to the value for evaporated films reported elsewhere [9, 12]. Figure (6) shows the baking temperature dependence of the refractive index at $740 \mathrm{~nm}$, the film thickness and the optical energy gap for only one sample. The rest of the multilayer samples showed the same behavior. From the inspection of Fig. 6 , it is clear that the refractive index of the films increases with the baking temperature while both the thickness and optical energy gap have decreased slightly.

The effect of the annealing time (In this case the samples were not baked before annealing) on the thickness of the multilayer samples, their refractive index and their energy gap is shown in Figure (7). The annealing sequence was started 3 hours after spin-coating. The samples were annealed for 2, 3, 5, 10, 25 and 30 min at temperatures of 90,120 and $150{ }^{\circ} \mathrm{C}$. The annealing time in the figure represents the total annealing time. One can see that, the thickness and refractive index are functions of both annealing time and temperature, although some saturation in the values was observed in the case of the $90{ }^{\circ} \mathrm{C}$ annealing. The tendency of the refractive index to increase and thickness to decrease with annealing time and temperature should be noted. This no doubts are related to the liberation of volatile from the organic solvent residue. 


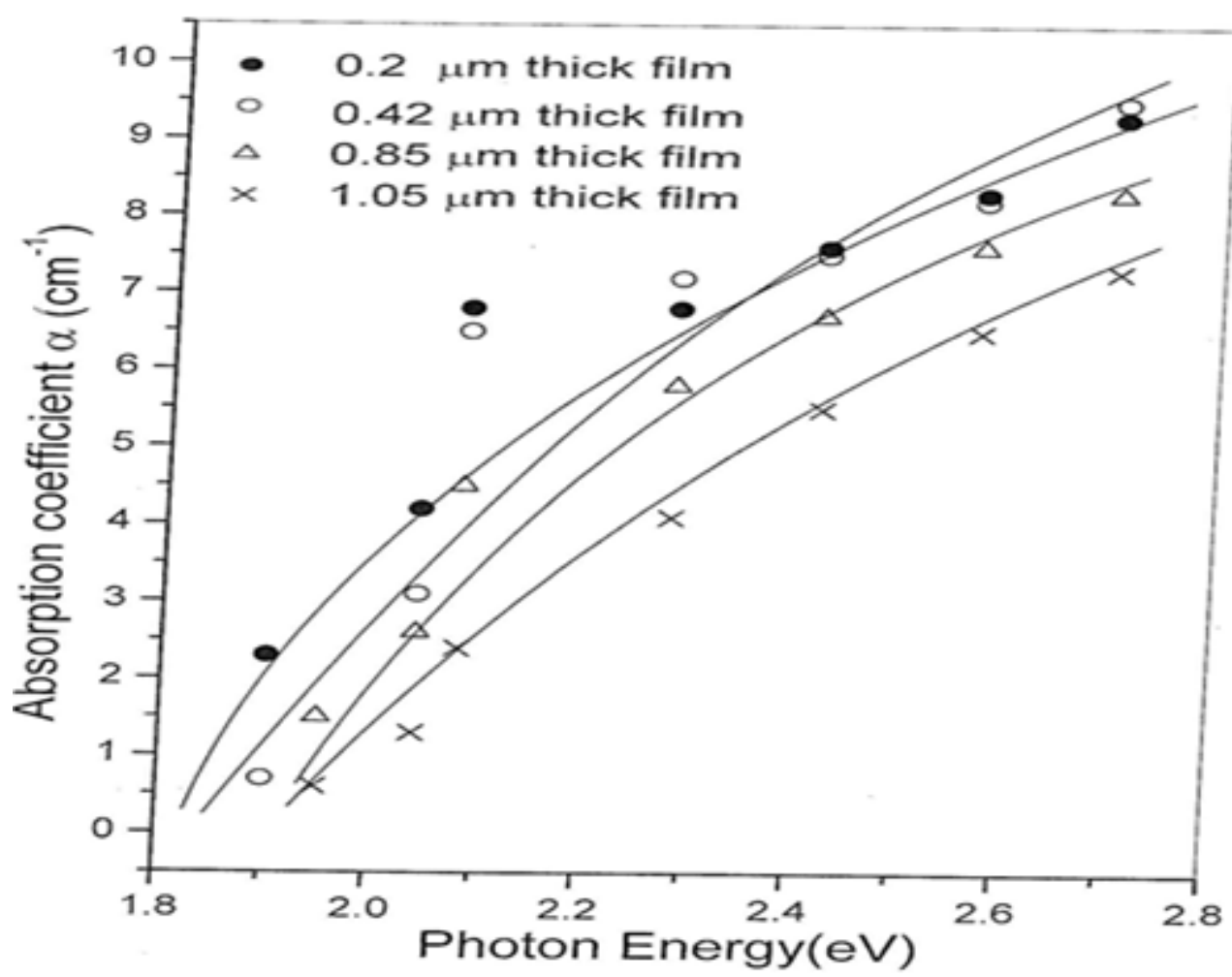

Fig. 4:- The absorption coefficient versus photon energy

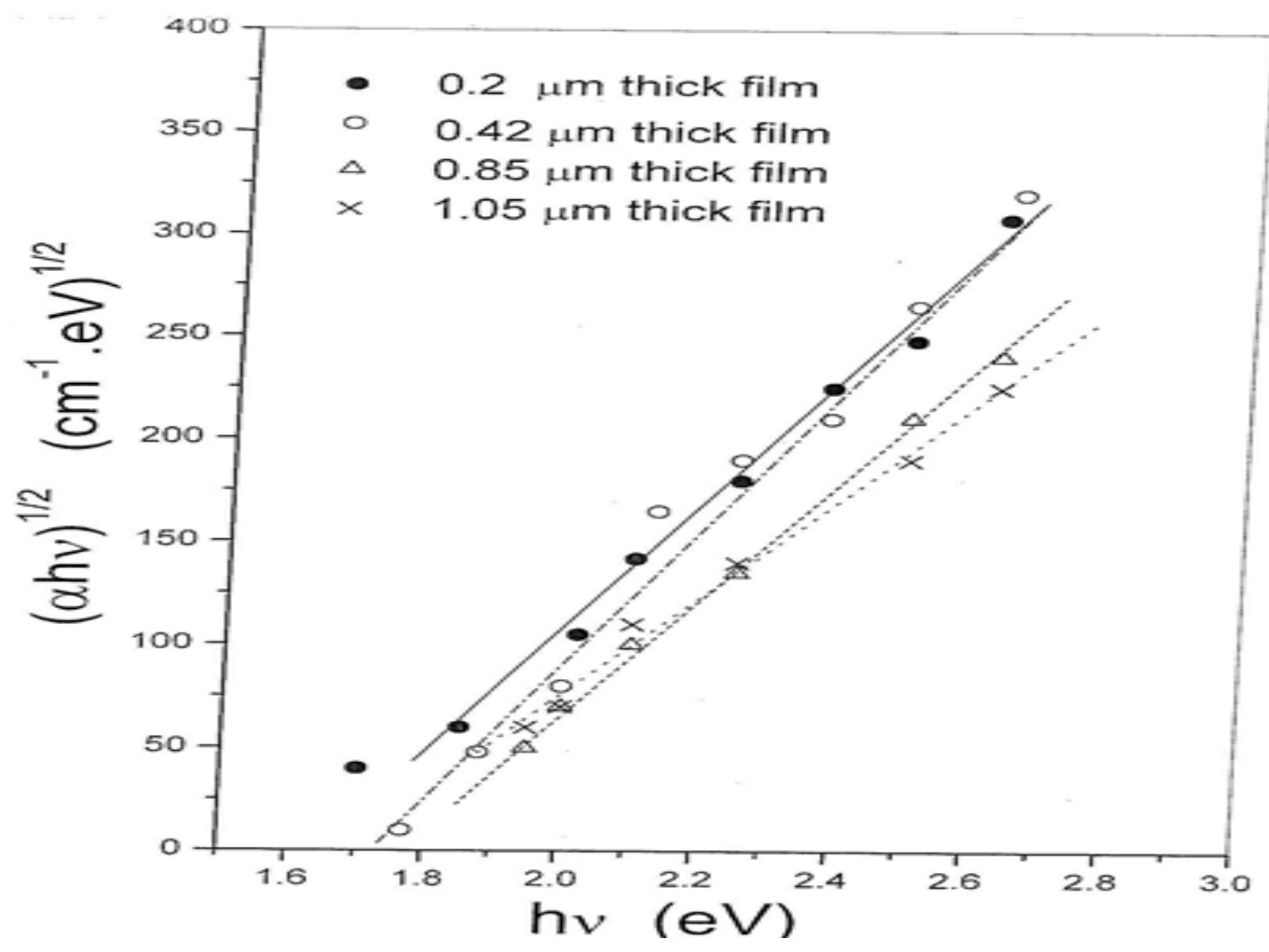

Fig. 5:-The optical energy gap versus photon energy 

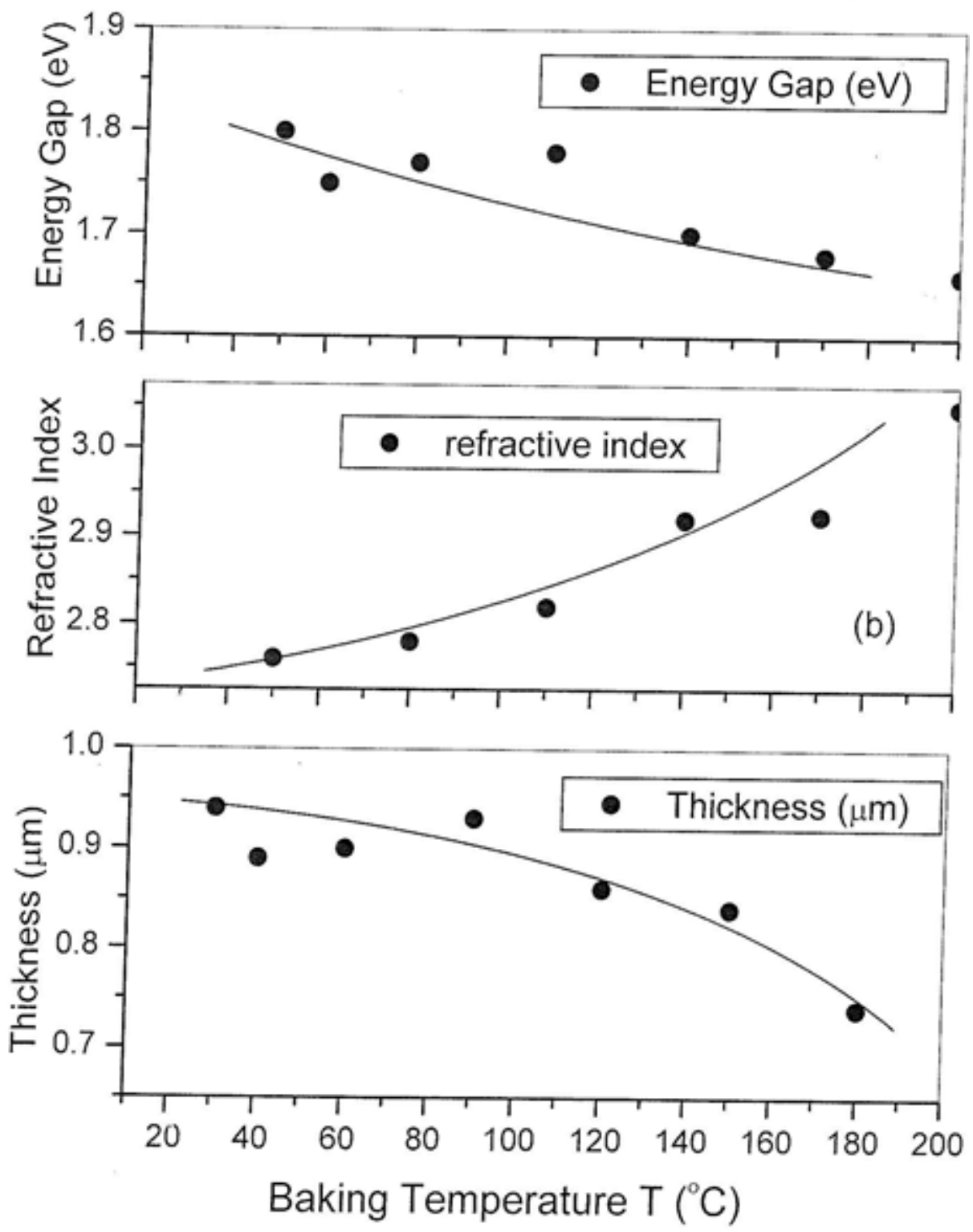

Fig. 6:- the baking temperature versus the refractive index at $740 \mathrm{~nm}$, the film thickness and the optical energy gap 

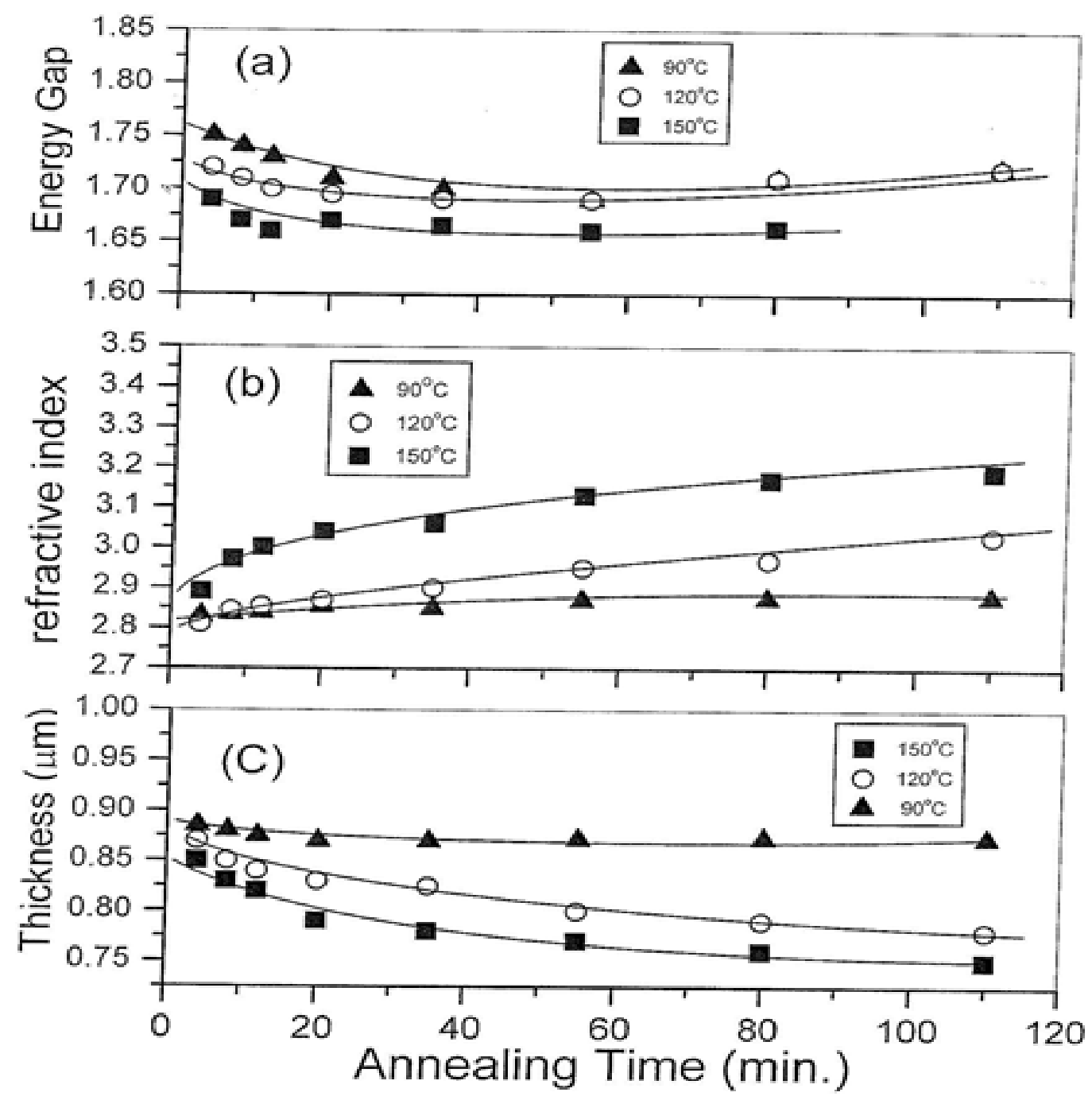

Fig. 7: annealing time versus the multilayer samples, their refractive index and energy gap

\section{Conclusion}

Multilayers of amorphous $\mathrm{As}_{2} \mathrm{Se}_{3}$ thin films have been successfully prepared by multiple spin coating of the dissolved material. The films obtained, up to four layers, have been optically characterized by measuring the optical transmission spectra of all the samples at room temperature. The refractive index and the optical energy gap of the studied films were found to be smaller than those of sputtered or thermally evaporated films probably because of the incorporation of carbon and hydrogen in the amine salt alkyl group. The organic residues, may be bonded to a negatively charged selenium dangling bond, seem to be responsible for the stability of the doubly dissolved material. The effect of the baking and annealing temperature on the optical parameters of the films were investigated. The thickness and refractive index were found to be functions of both annealing time and temperature. This is related to the liberation of volatile from the organic solvent residue.

\section{References}

1. N.F. Mott and E. A. Davis, Electronic processes in non-crystalline materials, $2^{\text {nd }}$ Ed., Clarendon, Oxford, 1979

2. M. Hammam, G.J. Adriaenssens, J. Dauwen, G. Seynhaeve and W. Grevendonk, J. Non- Cryst. Sol., 119 (1990) 89

3. M. Hammam, G.J. Adriaenssens and W. Grevendonk, J. Phys. C, Sol. St. Phys., 18 (1985) 2151

4. G.C. Chern, I. Lauks and K.H. Norian, Thin Solid Films, 123 (1985) 189

5. E. Bychkov, V. Tsegelink, Yu Viasov, A. Paradel and Ribs, J. Non- Cryst. Sol., 208 (1996) 1

6. B. Singh, G.C. Chern and I. Lauks, J. Vac. Sci. Technol., B, 3 (1985) 327

7. M. Hammam, M. Abdel Harith and W.H. Osman, Sol. St. Commun., $59: 5$ (1986) 271 
8. L. Vrions and W. Rippens, Appl. Opt., 22 (1983) 4105

9. R. Swanepoel, J. Phys. E, Sci. Instrum., 16 (1983) 1214 and 17 (1984) 896

10. E. Marquez, J.M. Gonzaler-Leal, R. Prieto-Aicon, M. Vick, A. Stronski, T. Wagner and D. Minkov, Appl. Phys. A67 (1998) 371

11. J.B. Ramirez-Malo, E. Marquez, P. Villares and R. Jimenez-Garay, Phys. Stat. Sol. (a), 133 (1992) 499

12. M. Ambrico, D. Smaldone, C. Spezzacatena, V. Stango, G. Perna and V. Capzzi, Semicond. Sci. Technol. 13 (1998) 1446

13. T. Toyo Da, J. Phys. D: Appl. Phys., 18 (1985) L129

14. A.M. Farid, Egypt. J. Sol., 25: 1 (2002) 23

15. J. B. Ramirez-Malo, E. Marquez, C. Corrales, P. Villares and R. Jimenez-Garay Sci. Eng. B, 25 (1994) 53

16. J.T. Tauc, Amorphous and liquid semiconductors, Ed. J. Tauc, Plenum, New York (1974)

17. N.A. Bakr, H. El-Hadidy, M. Hammam and M.D. Migahed, Thin Solid Films, 424 (2003) 296 